\title{
La restauración en situaciones límite de pérdida estructural. La imponente pila bautismal renacentista de la Iglesia de Santa María de Ontinyent (Valencia)
}

\author{
Xavier Mas-Barberà y María Duréndez-Hernández
}

Resumen: Este trabajo presenta el conjunto de estudios previos y tratamientos llevados a cabo en la emblemática pila bautismal renacentista de la iglesia de Santa María, de la población de Ontinyent (Valencia). Se trata de una pieza de grandes dimensiones $(150 \times 160 \times 160) \mathrm{cm}$, labrada en soporte pétreo, concretamente mármol de Carrara. La pieza presentaba una importante fracturación del fuste, que ponía en riesgo su permanencia, por lo que se hacía indispensable un exhaustivo diagnóstico del material y un sistema de refuerzo estructural. Este tratamiento se realizó atendiendo al difícil problema de tamaño, peso y emplazamiento de la propia obra, por lo que se diseñó una estructura de sostén móvil que desplazara el tazón y elevara el conjunto por medio de dispositivos hidráulicos. Ello permitió intervenir en la fuerte fragmentación del fuste y proporcionar estabilidad y solidez material a la obra. Asimismo, se diseñó una estructura de sacrificio reversible, como medida preventiva, que permitía restablecer su funcionalidad y garantizar la estabilidad del material original. En definitiva, este proyecto ha permitido recuperar una obra única y verdadero ejemplo de valor excepcional. La obra fue intervenida en el laboratorio de conservación y restauración de Materiales Pétreos y Ornamentales del Instituto Universitario de Restauración del Patrimonio de la Universidad Politécnica de Valencia.

Palabras clave: Restauración, adhesión, refuerzo estructural, pila bautismal, material pétreo, fragmentación

O restauro em situações limite de perca estrutural. A imponente pia baptismal renascentista da igreja de Santa Maria de Ontinyent (Valência)

Resumo: Este trabalho apresenta o conjunto de estudos prévios e tratamentos levados a cabo na emblemática pia baptismal renascentista da igreja de Santa Maria, na povoação de Ontinyent (Valência). Trata-se de uma peça de grandes dimensões $(150 \mathrm{~cm}$ x $160 \mathrm{~cm}$ x $160 \mathrm{~cm}$ ) lavrada em suporte pétreo, concretamente em mármore de Carrara. A peça apresentava uma importante fractura do fuste que punha em perigo a sua permanência, pelo que era indispensável um diagnóstico exaustivo do material e um sistema de reforço estrutural. Este tratamento foi realizado, tendo em conta o difícil problema de tamanho, peso e localização da própria peça, pelo que se desenhou uma estrutura de sustentação móvel que deslocará a taça e elevará o conjunto através de dispositivos hidráulicos. Isso permitiu intervir na grande fragmentação do fuste e proporcionar estabilidade e solidez material à obra. No entanto, concebeu-se uma estrutura de sacrifício reversível, como medida preventiva, que permitia restabelecer a sua funcionalidade e garantir a estabilidade do material original. Em suma, este projecto permitiu recuperar uma obra única e um verdadeiro exemplo de valor excepcional. A obra foi intervencionada no laboratório de conservação e restauro de Materiais Pétreos e Ornamentais do Instituto Universitário de Restauro do Património da Universidade Politécnica de Valência.

Palavras-chave: Restauro, adesão, reforço estrutural, pia baptismal, material pétreo, fragmentação.

Restoration in the extreme situation of structural loss. The monumental renascentist baptismal font of the church of Santa Maria in Ontinyent (Valencia).

\begin{abstract}
This paper presents the results of a whole set of preliminary studies and treatments carried out on the emblematic renascentist baptismal font of the church of Santa Maria in the town of Ontinyent (Valencia). It is a large piece $(150 \mathrm{~cm} \times 160 \mathrm{~cm} \times 160 \mathrm{~cm})$, carved in a Carrara marble stone support, and a significant fracture of the shaft was threatening its permanence. Therefore a thorough analysis of the material and structural reinforcement system was indispensable. The treatment was carried out taking account of the difficult size, weight and location problem of the piece itself by considering the design of a mobile support structure that displaced the bowl, and elevated the whole using hydraulic devices. This allowed the intervention of the strongly fragmented shaft providing stability and solidity to the work. In addition, a reversible sacrificial structure was designed as a preventive measure, which allowed re-establishing its functionality and guaranteeing the safety of the material. In conclusion, this project has enabled the recovery of a unique work and a real example of exceptional value. The work was executed by the conservation and restoration laboratory of stone and ornamental materials of the Heritage Conservation Institute of the Polytechnic University of Valencia.
\end{abstract}

Keywords: Restoration, adhesion, structural reinforcement, font, stone material, fragmentation. 


\section{Introducción}

La pila bautismal de Santa María de Ontinyent (Valencia) fue adquirida en Italia por el clero parroquial en el siglo XVII. De estilo renacentista, es una obra labrada en mármol de Carrara a manos de artistas de escuela florentina. En ella se manifiesta un espléndido trabajo de finas y delicadas esculturas y ornamentos en relieve que la convierten en una obra única de valor excepcional. La pila bautismal está formada por tres partes bien diferenciadas: el vaso y/o receptáculo del agua sagrada, el fuste-columna de sostén y la basa [figura 1]. Por un lado, el vaso o pila del bautismo en forma circular muestra ocho querubines alados, sinuosas acanaladuras, así como un espléndido juego de flores de acanto que cierra y la separa de la segunda parte de la composición. Por otro lado, en el fuste o soporte de la pila se encuentran también cuatro finos relieves de cabecitas de querubines y ornamentación floral. Finalmente, la basa en forma cuadrangular cierra la composición con un juego sutil de cuadrados concéntricos y medias cañas biseladas.

La pila bautismal está tallada en piedra mármol de Carrara. Desde el punto de vista artístico, este tipo de roca fue muy apreciado entre los escultores de la época debido a su facilidad para la labra, tamaño de mineral y blancura en el acabado. Pero este no es el caso de nuestra obra, pues al tratarse de un elemento funcional/ornamental y no estatuario, el material pétreo admitía la heterogeneidad. En la localidad de Carrara son muchas las canteras que extraen el mármol, pero pocas poseen el famoso mármol blanco estatuario, el elegido por Miguel Ángel para sus esculturas. Existe una gran variedad de mármoles de Carrara, desde el blanco "lechoso" hasta el gris oscuro bardiglio". Actualmente, y como en la antigüedad, sigue habiendo variedades de Carrara, reservándose las piezas más limpias para la escultura, lo que conlleva un coste económico al alcance de pocos. Por el contrario, el resto de calidades se empleaban para fines no estatuarios, como por ejemplo, escaleras, columnas, dinteles, suelos, zócalos, altares, entre otros, como en el caso que nos atañe. No obstante, contrasta vivamente la labra sinuosa, suelta y monumental, con la desafortunada elección del material, ya que tanto el vaso como el fuste presentan varios "pelos" con un riesgo considerable de ruptura.
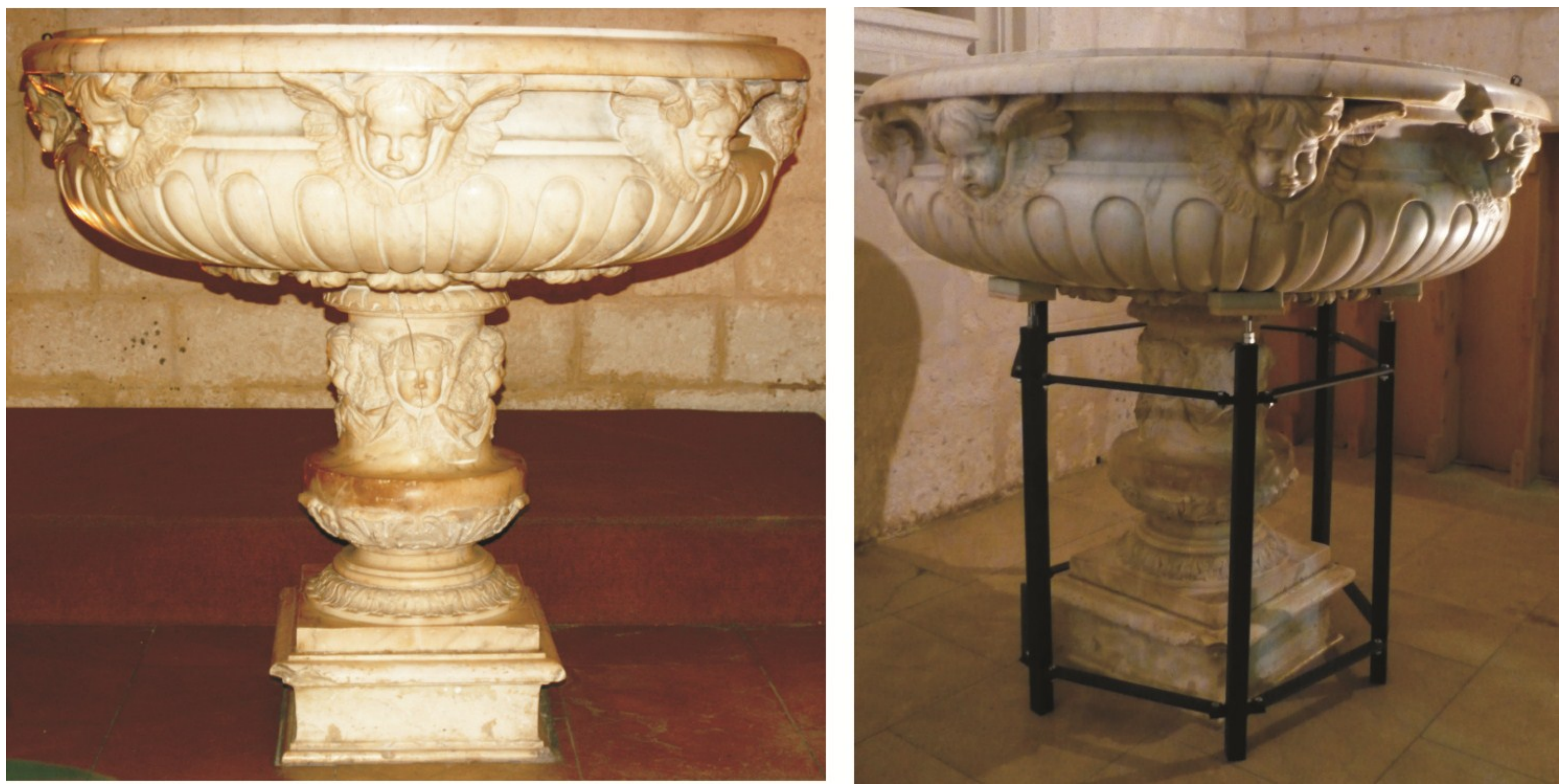

Figura 1. Vista general de la pila bautismal (2005). Vista general de la pila bautismal con sistemas preventivos de sostén (2008). 


\section{Estado de Conservación}

La pila bautismal de la iglesia de Santa María de Ontinyent presentaba un cuadro patológico que comprometía, por un lado su lectura estética y, por otro su perdurabilidad funcional e histórica.

En cuanto a la problemática de índole más estética, ésta se debía a varios factores como la acumulación de suciedad diversa (restos de morteros, manchas de óxidos, polvo, cera, entre otros), las pérdidas de volúmenes pertenecientes a molduras y salientes de la pila y también causados por intervenciones anteriores desafortunadas (traslado de su lugar original junto a la puerta principal del templo hasta su lugar actual, una capillita lateral) [figura 2].

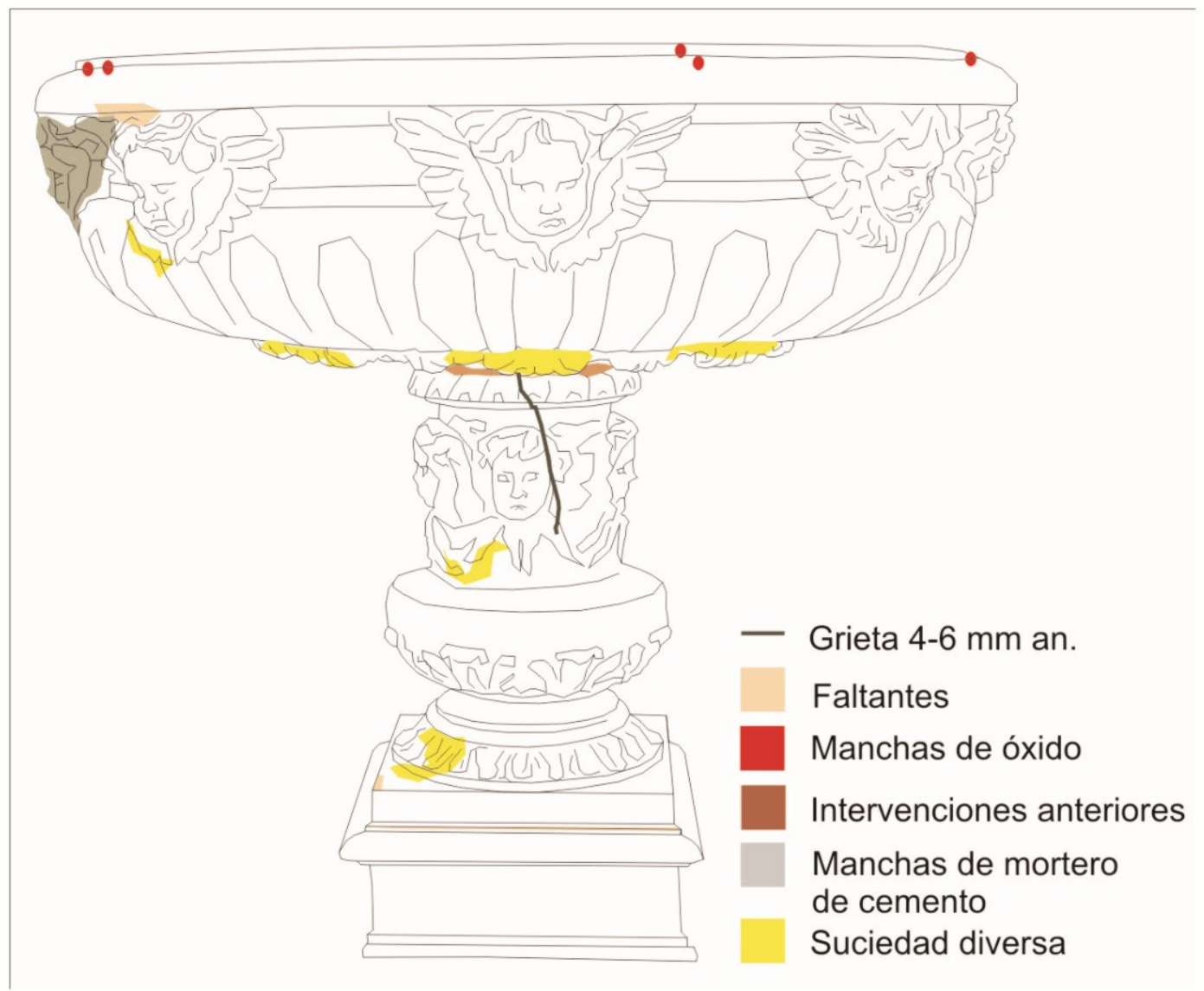

Figura 2. Cartografía de la patología del reverso de la pila bautismal.

Pero el deterioro que realmente cuestionaba la perdurabilidad y consistencia de la pila correspondía a la presencia de varias grietas transversales de varios milímetros de anchura situadas a lo largo del fuste de la obra. La presencia de estas grietas se debieron, como veremos en el apartado siguiente, a la presencia de una gruesa varilla de hierro forjado insertada a lo largo de toda la pieza, intervención que podría haberse realizado en los años cuarenta del siglo XX, durante los trabajos de reubicación de la obra. Esta pieza metálica ha ido aumentando de volumen a consecuencia de la humedad, ocasionando la alteración físicomecánica-química citada. Por tanto, este daño estructural ponía de manifiesto la importancia de acometer rápidamente una intervención de consolidación y refuerzo estructural con el fin de devolverle su unidad material ante el grave peligro de rotura y caída de la misma [figura 3]. 

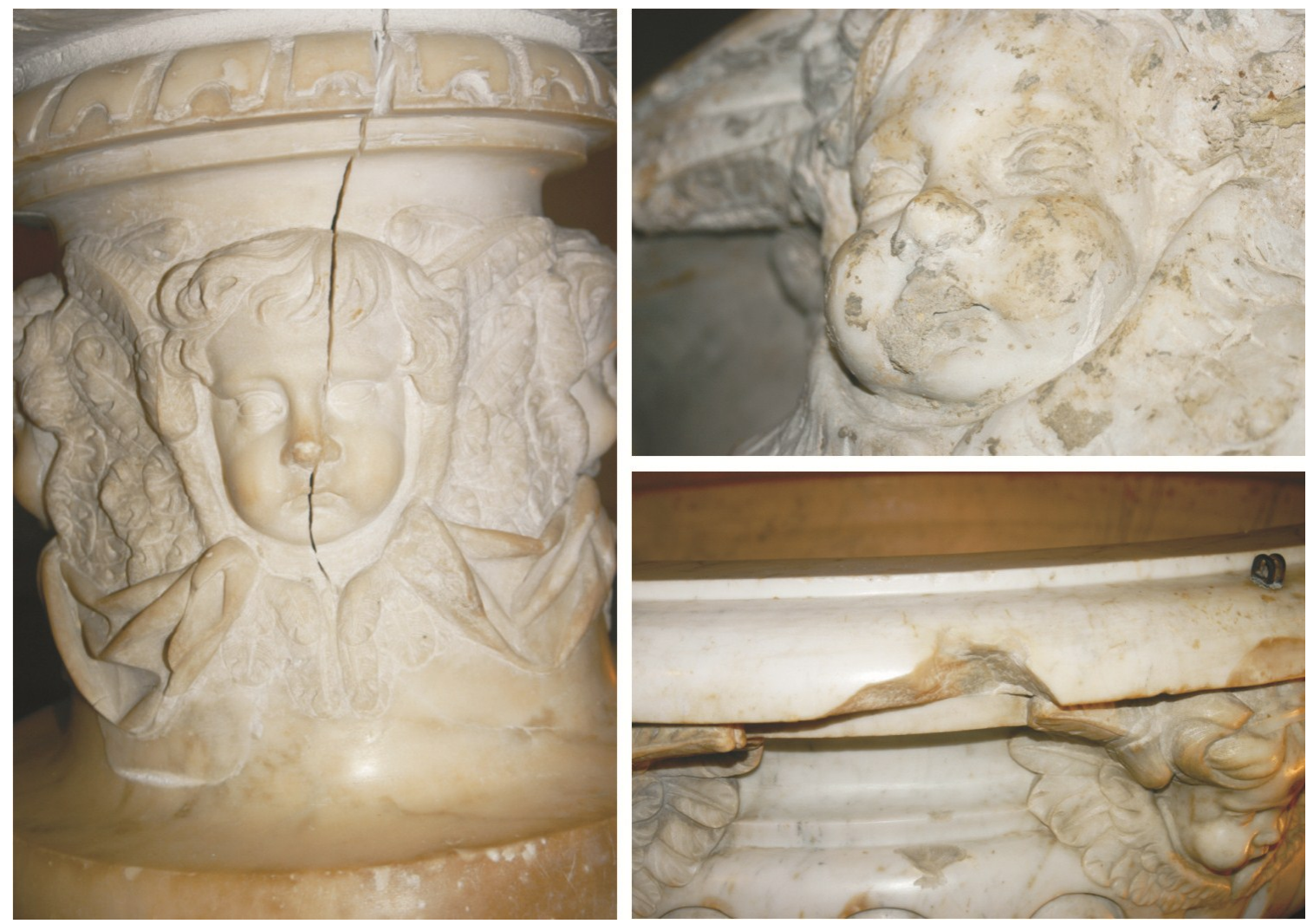

Figura 3. Presencia de la grieta de la estructura. Restos de morteros de cemento procedentes de intervenciones anteriores fuertemente adheridos al soporte marmóreo. Pérdida de volúmenes correspondientes a las molduras de los perfiles superiores de la pila.

\section{Diseño y realización de la estructura portante}

Realizados los estudios previos de diagnóstico de la obra y prospección del emplazamiento, el equipo de trabajo concluyó que la intervención era complicada debido no sólo al tamaño y gran peso de la pila, sino también a su ubicación, puesto que era inviable para su traslado emplear maquinaria pesada por el interior de la iglesia, al tratarse de un edificio que presenta criptas subterráneas.

De este modo se estimó diseñar una estructura de sostén móvil que desplazara el tazón y elevara el conjunto por medio de dispositivos hidráulicos, evitando el máximo estrés a la obra y moviéndola escasos centímetros de su lugar original. Para ello, se calculó el peso aproximado del tazón (estimación en torno a $1.800 \mathrm{~kg}$, según el ingeniero calculista) y se distribuyeron los pesos en la estructura metálica a lo largo de seis ejes localizados respecto al centro de plomada y librando las hojas de acanto ornamentales. Esta estructura debía moverse sutilmente por debajo de la taza, apoyarse sobre una base estable y servir de apoyo, elevarse de manera que permitiera el alzado de la obra y desplazarse con todo el peso a lo largo de un metro de distancia, el cual permitiría el trabajo en la parte del fuste y base. El resultado fue una estructura metálica estable obtenida a partir de seis viguetas IPN-160 colocadas verticalmente, formando un hexágono (dotadas con piezas de amortiguamiento en su parte superior que evitaban cualquier daño en la decoración ornamental), y cargadas sobre dos viguetas horizontales. Asimismo, la estructura era movida mediante doce ruedas dispuestas en cuatro pletinas roscadas y reversibles. El alzado del total de la estructura y la obra se conseguía mediante cuatro dispositivos hidráulicos (más dos de apoyo) capaces de levantar dos toneladas de peso cada uno. En definitiva, la estructura garantizaba el desplazamiento de la obra y la mantenía suspendida durante el proceso de intervención [véase la figura 4]. 


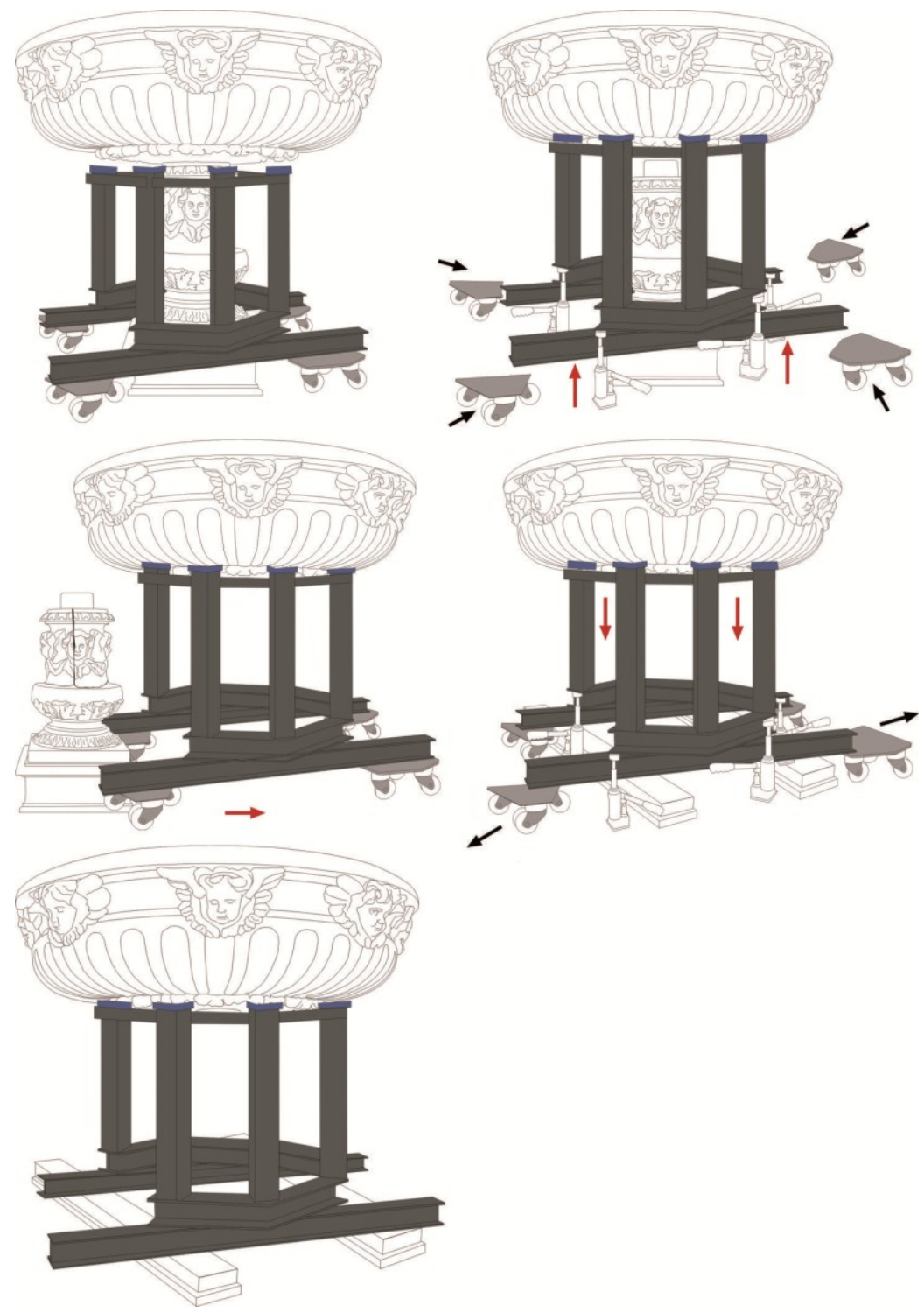

Figura 4. Estructura metálica de sostén móvil con dispositivos hidráulicos creada para el alzado de la pila bautismal. Peso estimado de izado: $1800 \mathrm{~kg}$.

\section{Proceso de intervención}

\subsection{Criterios de intervención}

Los objetivos generales de la intervención se han centrado en desmontar la pila para recuperar la consistencia estructural del fuste, restablecer el aspecto estético eliminando suciedades y añadidos, reconstruir partes perdidas, y adoptar medidas de protección frente a la actividad litúrgica. Los criterios de actuación adoptados recogían diferentes aspectos como rigurosidad y responsabilidad hacia la obra, reversibilidad y mínima intervención, y adecuación de las nuevas tecnologías al mundo de la restauración de obras de arte. Toda la intervención quedó registrada mediante documentación fotográfica digital y 
grabaciones del proceso, así como la extracción y análisis de muestras de los diferentes materiales (piedra, metal, morteros, entre otros) y medidas ambientales (térmicas y $\mathrm{hR}$ ).

\subsection{Desmontaje de las partes que conforman la pila: el vaso y el fuste}

En primer término se creó la estructura metálica móvil que, mediante seis elevadores hidráulicos, alzaba el vaso de su apoyo desplazándola para ser intervenida.

Durante el alzado y posterior desplazamiento de la pila se evidenció el estado de ruptura en el que se encontraba el fuste [véase la figura 5]. El proceso de levantamiento fue complicado ya que a medida que el vaso y el fuste se separaban, las partes del fuste con grietas se iban fragmentando, ello se debía a la presión a modo de cuña que ejercían los pequeños trozos internos desprendidos. Tras un estudio de la situación se tomó la decisión de separar el fuste completamente en cuatro partes coincidiendo con las enormes grietas longitudinales que lo atravesaban [figura 6]. Esta medida permitió ahondar en las sucesivas fases de limpieza y consolidación del fuste obteniendo óptimos resultados de cohesión estructural, como se detallará en los siguientes apartados.
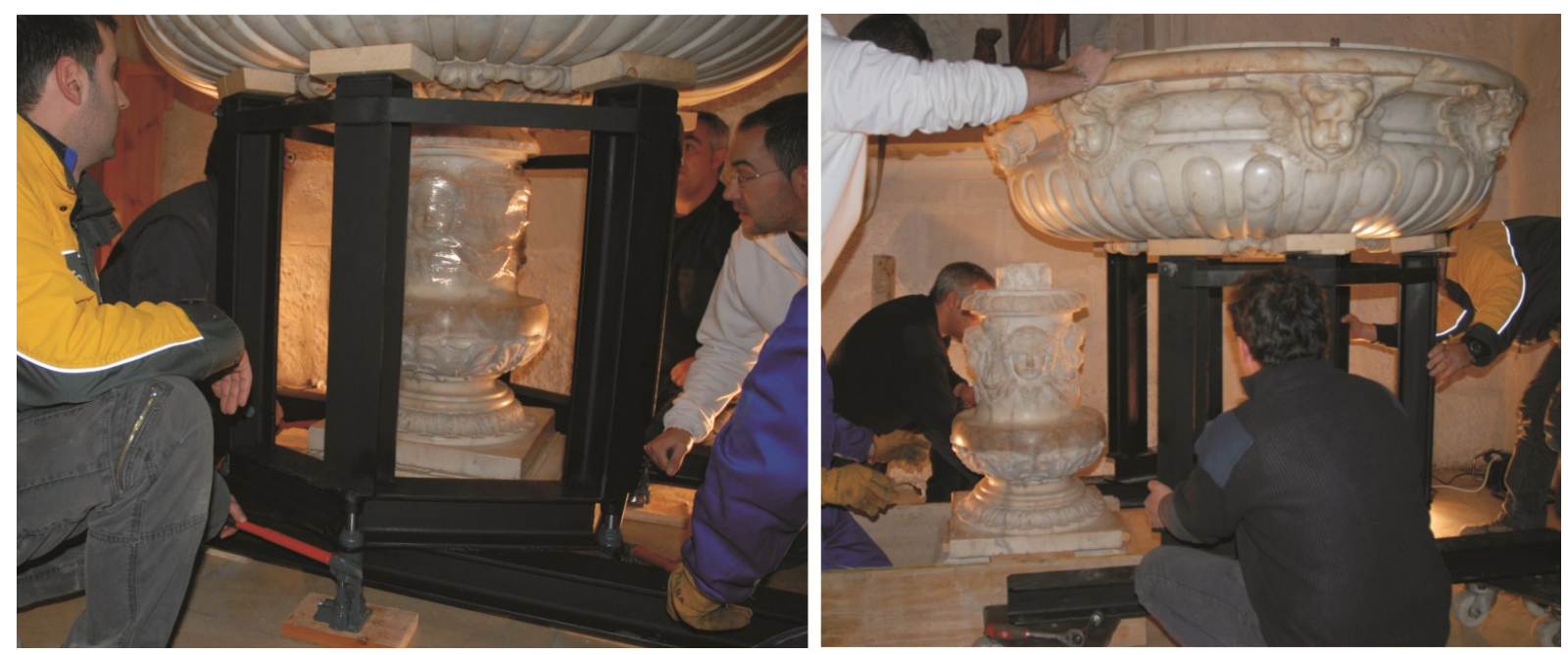

Figura 5. Preparación del dispositivo de sostén, elevación de la pieza y traslado.

\subsection{Limpieza mecánica y eliminación de morteros añadidos}

Se ha efectuado una exhaustiva fase de limpieza mecánica de toda la superficie de la pila bautismal eliminándose, por un lado, todas las piezas metálicas corroídas y derivados altamente oxidados y, por otro lado, la presencia de restos de morteros de cemento adheridos al soporte marmóreo. Para ello, se han empleado utensilios de precisión (bisturís y escalpelos), micromotores, microincisores y ultrasonidos, así como taladros con brocas de diferentes diámetros y longitudes que han permitido extraer el grueso perno corroído. Esta primera fase de limpieza mecánica se estimó oportuna puesto que la premisa inicial era extraer todos los elementos extraños inherentes a la obra, sin causarle reacción alguna. Principalmente, las piezas y trozos del fuste con una proporción elevada de herrumbre fueron limpiados concienzudamente de forma que las fases de encolado y reconstrucción no se vieran mermadas. 
Xavier Mas-Barberà y María Duréndez-Hernández

La restauración en situaciones límite de pérdida estructural. La imponente pila bautismal renacentista de la Iglesia de Santa María de Ontinyent (Valencia)
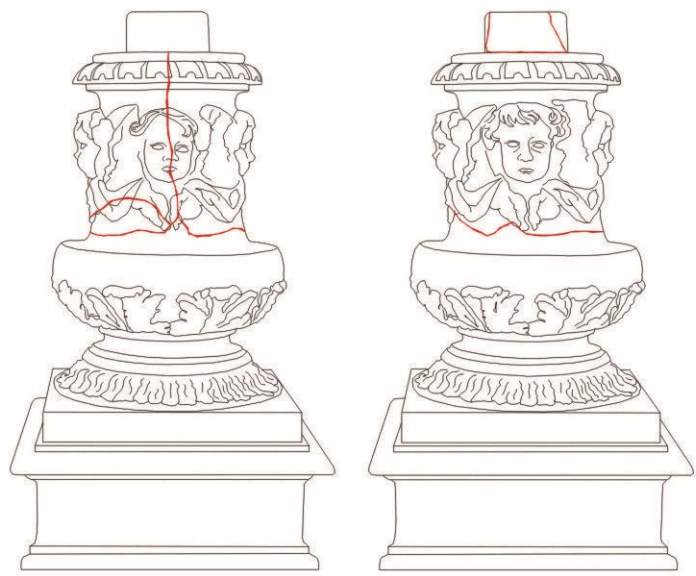

Fuste: vista frontal.

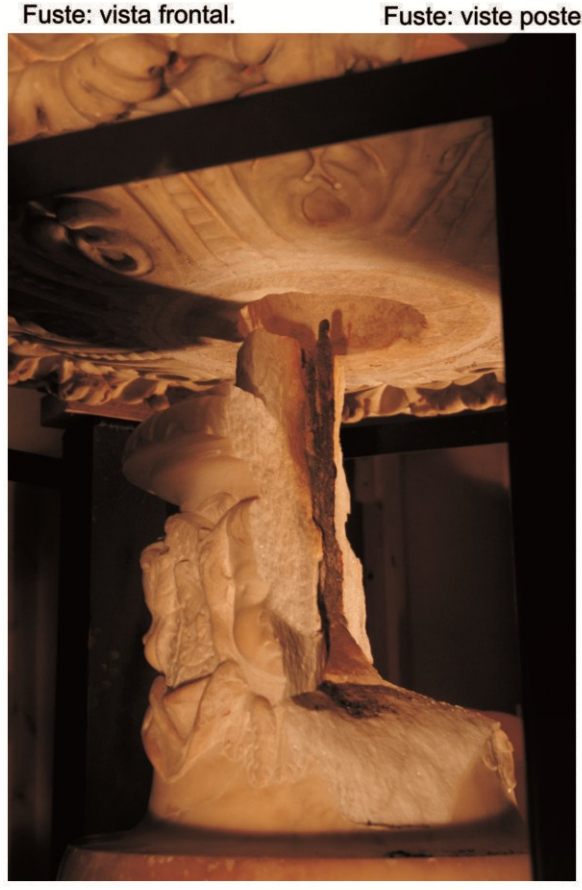

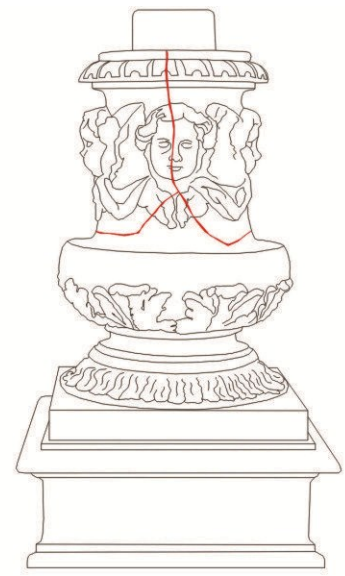

Fuste; lateral derecho.

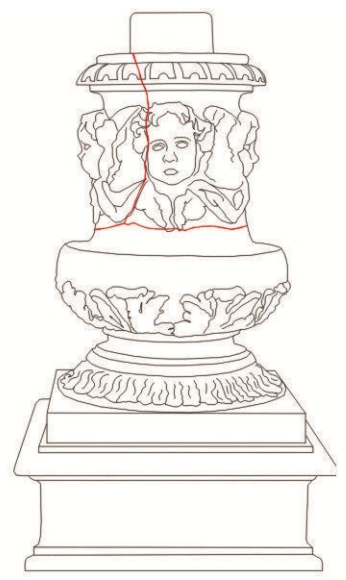

Fuste: lateral izquierdo.

Fuste: líneas de fractura.

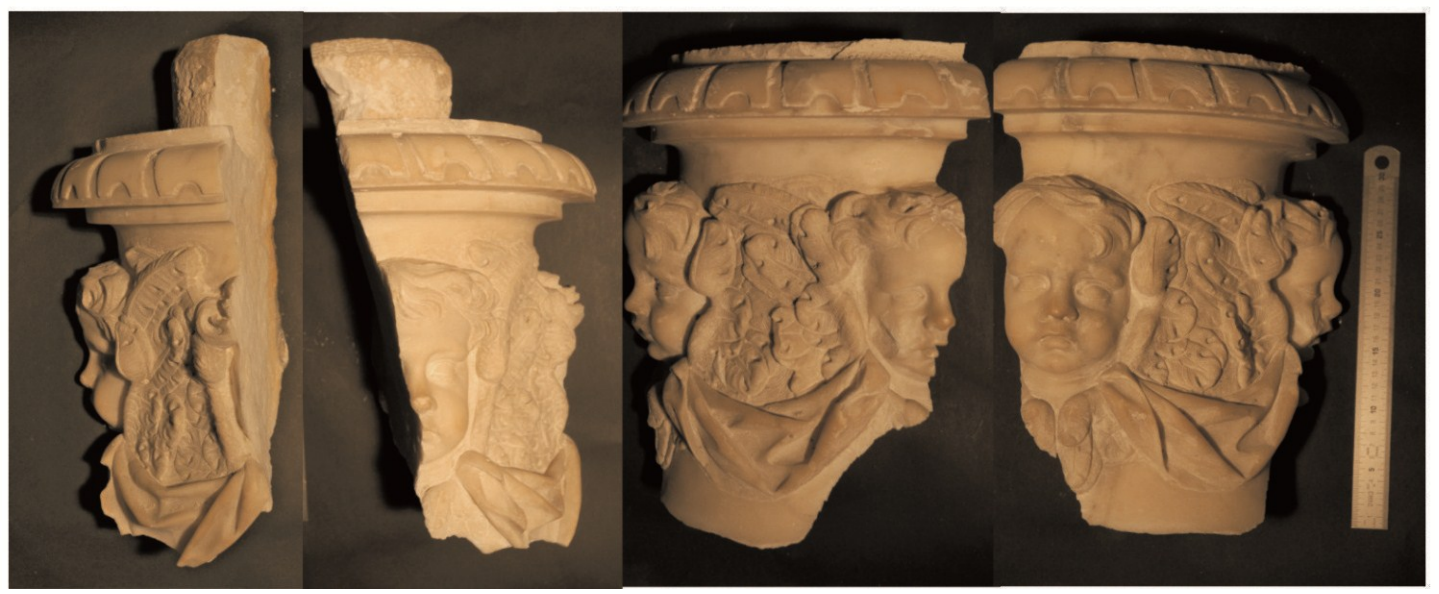

Figura 6. Separación de la pila del fuste mediante la estructura metálica móvil. Obsérvese la varilla de acero forjado actuando de eje central. Resultado del desmembramiento del fuste. Fragmentación total. 


\subsection{Limpieza química}

La limpieza química se ha llevado a cabo en la totalidad de la pieza, mediante el empleo de sustancias de composición neutra y eliminando la presencia de manchas de polvo incrustado, cera oxidada, restos de barnices y suciedad en general. Varias han sido las disoluciones empleadas tras la realización de las catas de solubilidad pertinentes. Por un lado, y en las zonas con polvo incrustado, se ha efectuado una limpieza con 2A (alcohol/acetona 1:1), así como con white spirit/alcohol isopropílico/acetona/amoníaco $(1: 1: 1: 0,5)$. Por otro lado, en las zonas con mayor depósito, como las inferiores de la taza, se han usado emplastes de papel japonés y disolvente no saturado (white spirit), seguido de una remoción con acetona y retoque con disolución de bicarbonato de amonio al 15\% en agua destilada. Los restos de cemento se han tratado, tras la limpieza mecánica, con emplastes de agua destilada y, acetona más escalpelo [figura 7]. Durante esta fase se ha tenido especial cuidado con los elementos escultóricos (cabezas de los ángeles alados) y detalles ornamentales (hojas de acanto), pues presentaban zonas con cierta abrasión y pequeños golpes. Asimismo, la limpieza ha sido suave y muy selectiva, manteniendo la pátina del tiempo característica de los mármoles de Carrara.
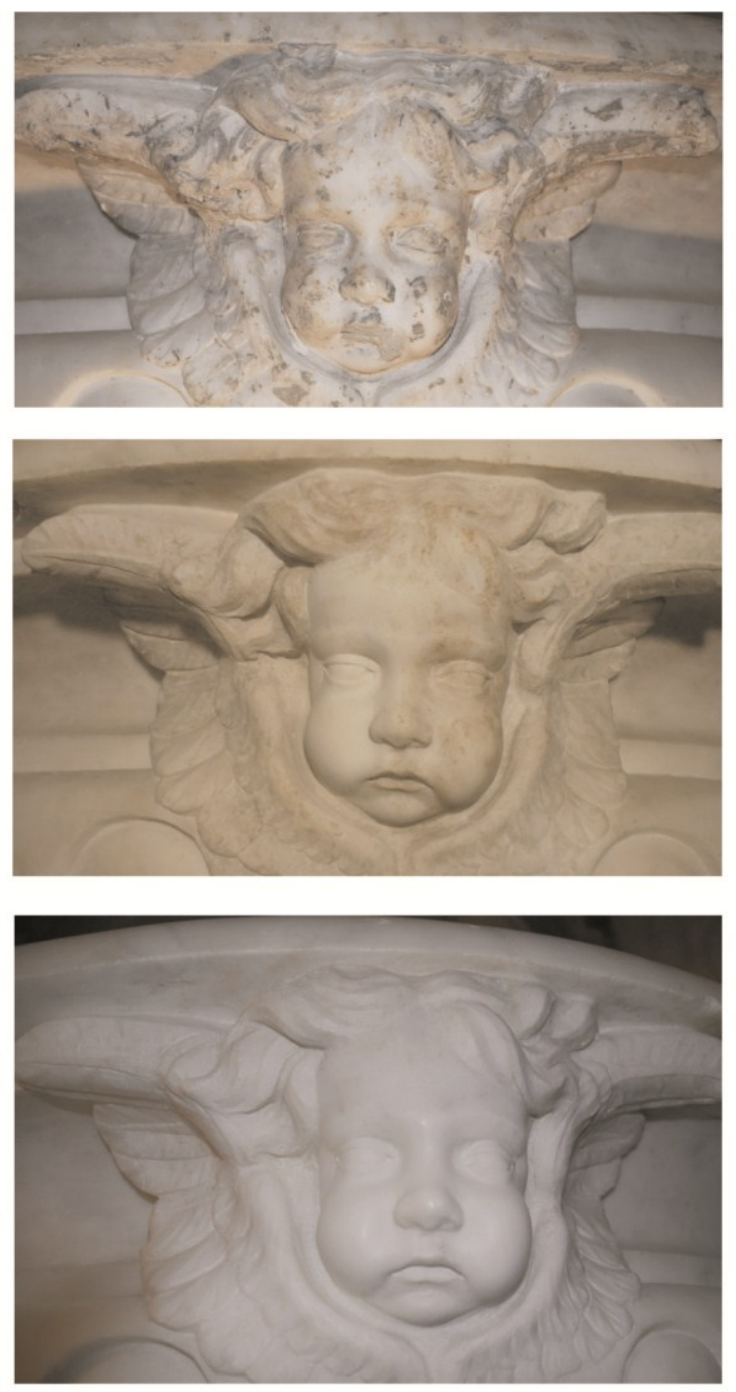

Figura 7. Estado de conservación de uno de los querubines de la pila con presencia de mortero de cemento. Estado del querubín tras la limpieza mecánica e inicio de la limpieza química. Resultado final tras la limpieza química. 


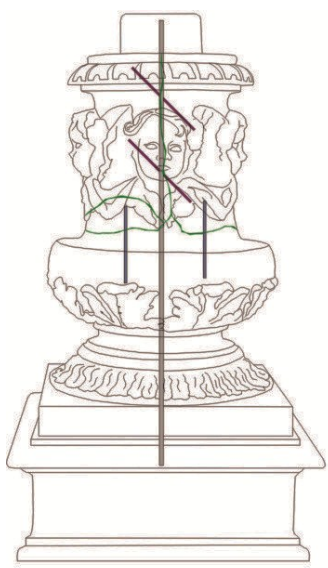

Fuste: vista frontal.

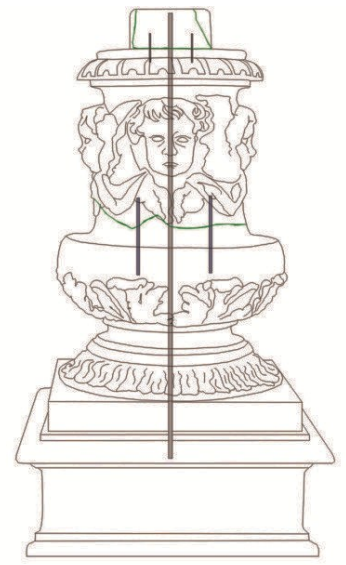

Fuste: Vista posterior.

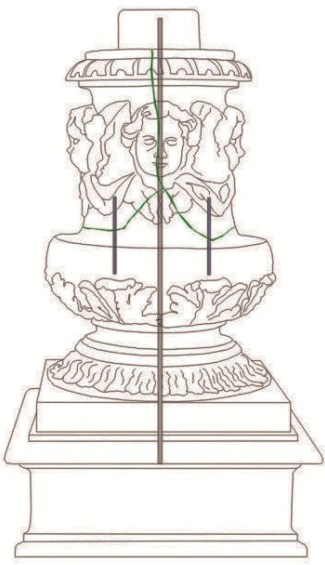

Fuste: lateral derecho.

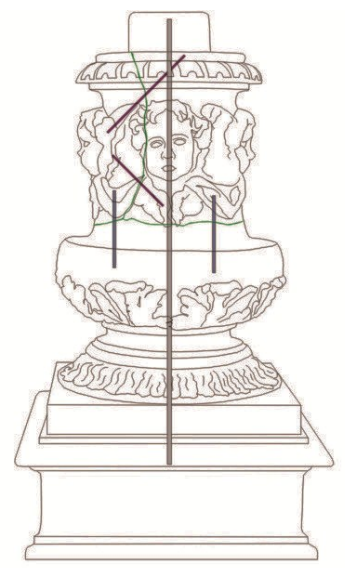

Fuste: lateral izquierdo.

Fuste: líneas de fractura

Pernos de fibra de vidrio. ( $\varnothing 6 \mathrm{~mm}$.)

Pernos de fibra de vidrio. $(\varnothing 10 \mathrm{~mm}$.)

Varilla central acero inoxidable. ( $\varnothing 30 \mathrm{~mm}$.)
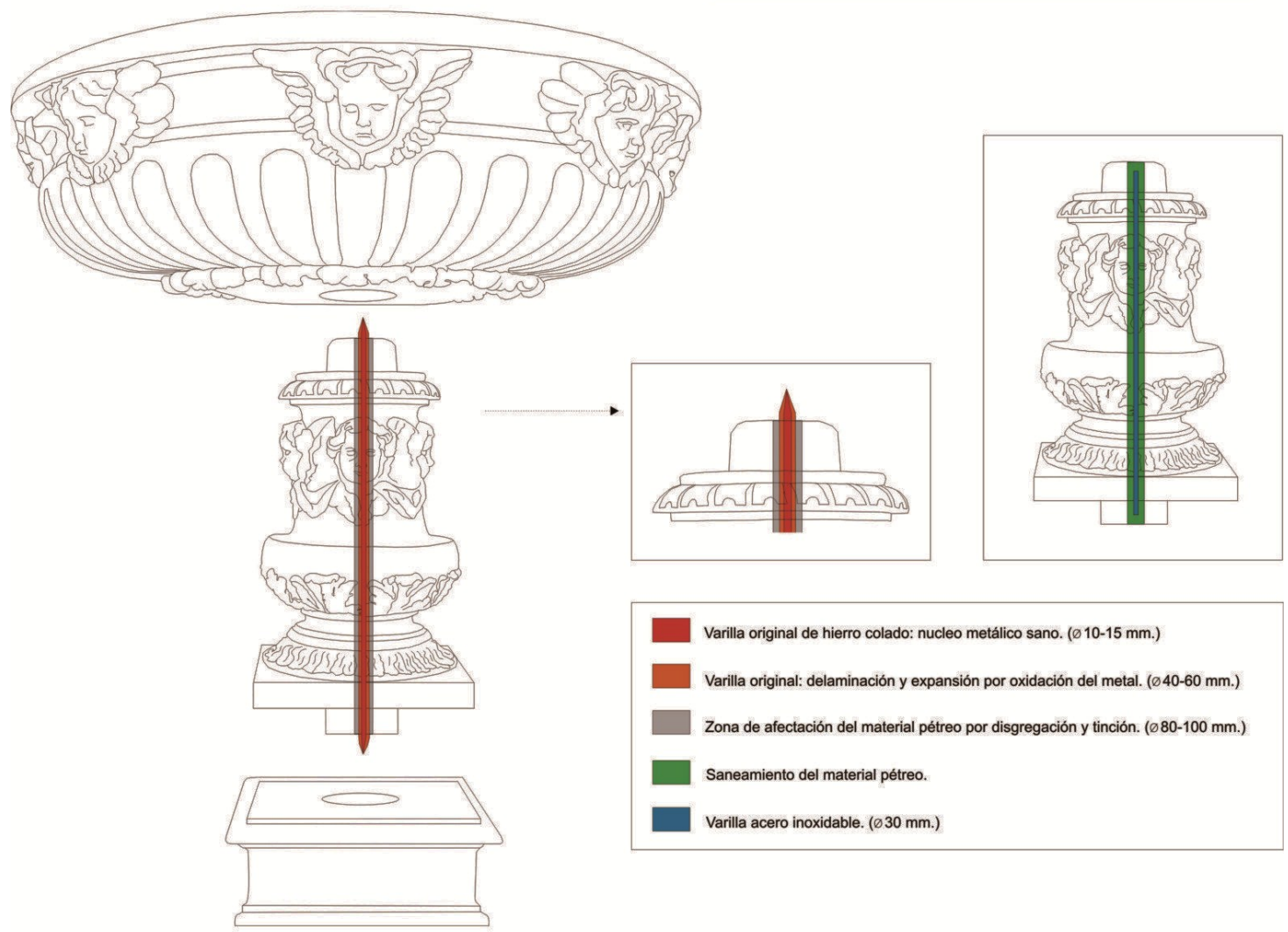

Varilla original de hierro colado: nucleo metálico sano. (ø 10-15 mm.)

Varilla original: delaminación y expansión por oxidación del metal. ( $\varnothing 40-60 \mathrm{~mm}$.)

Zona de afectación del material pétreo por disgregación y tinción. ( $(80-100 \mathrm{~mm}$.)

Saneamiento del material pétreo

Varilla acero inoxidable. $(\varnothing 30 \mathrm{~mm}$.)

Figura 8. Fase de estudio para el proceso de cosido y encolado de fragmentos. Localización de pernos y propuesta de tratamiento. 


\subsection{Tratamiento del volumen}

Este apartado, de relevancia destacada, pone de relieve la reconstrucción volumétrica y formal llevada a cabo en la totalidad de la obra. Las diferentes actuaciones, en cuanto al tratamiento del volumen se refiere, se detallan a continuación:

\subsubsection{Cosidos y anclajes de fragmentos}

La primera actuación se centró en la sustitución de la varilla de hierro forjado, eliminada en la fase de limpieza mecánica, por otra de acero inoxidable de $30 \mathrm{~mm}$ de diámetro por $1120 \mathrm{~mm}$ de longitud [figura 8]. La colocación de la nueva varilla se estimó en base al centro radial del fuste y "a plomo". Así mismo, los cuatro fragmentos que conformaban el fuste fueron unidos dos a dos de manera que resultaron finalmente dos partes: anverso y reverso. El encolado se realizó mediante una resina epoxi tyxotrópica (Araldit Standard de Ceys) con altas prestaciones de resistencias mecánicas a compresión y flexotracción. Paralelamente, las cuatro partes fueron cosidas entre sí mediante varillas de fibra de vidrio de $6 \mathrm{~mm}$ de diámetro. Finalmente, anverso-reverso del fuste fueron encolados uniéndolos perfectamente mediante tensores textiles y gatos prensadores [véase la figura 9]. Mediante un mortero de matriz sintética, formado por una resina epoxi de colada (EPO 150 de CTS) y una carga de carbonato cálcico $(800 \mu)$ en proporción 1:3 vol., se llenó el vacío entre la varilla de acero inoxidable de $30 \mathrm{~mm}$ y el soporte pétreo, obteniéndose un eje central resistente, fiable y cohesionado. El sistema mixto encolado-cosido, mediante refuerzo de barras de fibra de vidrio, se valoró de acuerdo a la exigencia que debía cumplir el fuste para resistir un fuerte esfuerzo a compresión y, en menor medida, a flexión. Asimismo, el diámetro y la profundidad del orificio de la espiga de refuerzo queda sujeta al tamaño de las partes a unir, el estado del soporte (si está sano o no) y la resistencia a soportar.
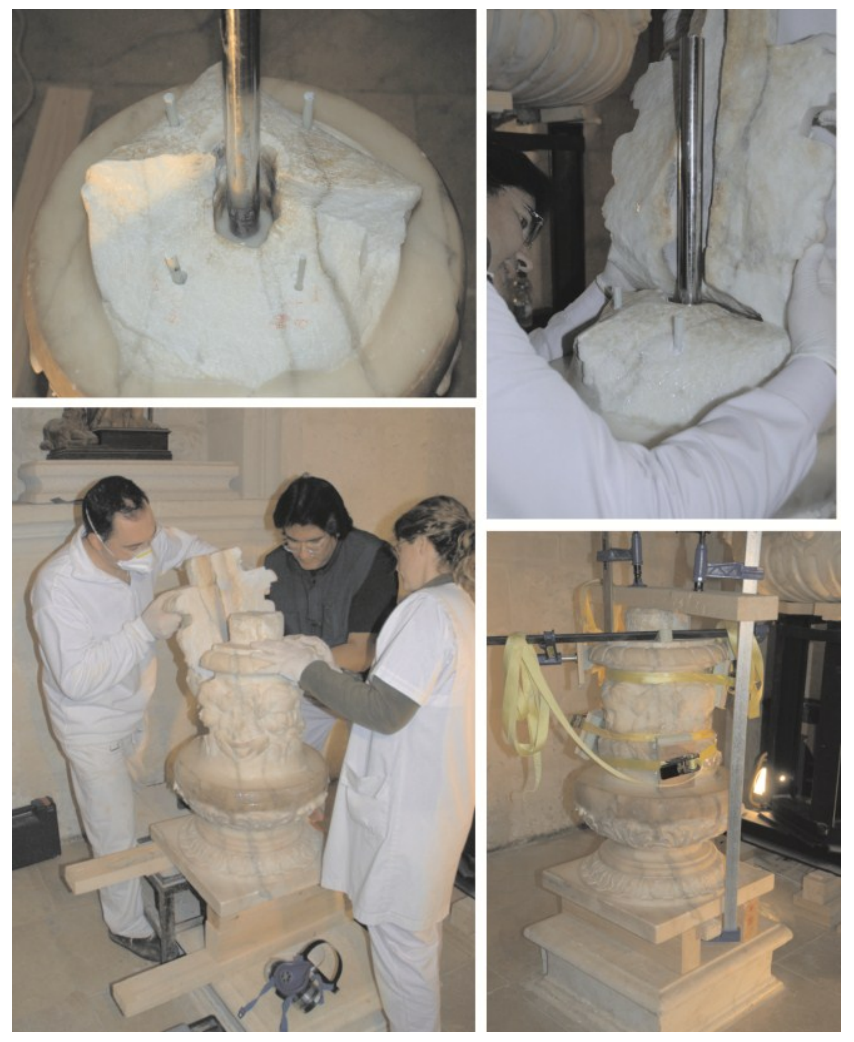

Figura 9. Varilla de acero inoxidable actuando de eje central. Fase de unión anverso-reverso del fuste alrededor del eje central. Obsérvese la presencia de varillas de fibra de vidrio en posición vertical reforzando la unión entre los fragmentos a la pieza central. Fase de pegado de las piezas que conforman el fuste. Estado del fuste durante el proceso de engatillado y prensado total. 


\subsubsection{Reintegración de faltantes}

Las lagunas de pequeño y mediano tamaño, que interferían en la lectura estética del conjunto, se recuperaron imitando el original. Para ello, y tratándose de una pieza de escasa porosidad y acabado pulido, se empleó un mortero de matriz sintética, formado por un conglomerante poliéster (Serifix de Struers), una carga de carbonato cálcico (mixto 300-800 $\mu$ ) y un aditivo de color (pigmentos inorgánicos) que le confería la tonalidad idónea. La aplicación se desarrolló in situ, modelando directamente el volumen sobre la zona de fractura, o mediante el ajuste de prótesis extraídas a partir del moldeado con plastilina y posterior llenado con morteros de matriz sintética coloreados.

Por otro lado, se llevaron a cabo pequeños sellados y estucados de fisuras con el fin de evitar la penetración y/o acumulación de agentes de deterioro (agua, polvo...) devolviéndole, asimismo, la coherencia estética al conjunto. Para ello, se eligió de nuevo el mortero de matriz sintética termoendurecible (conglomerante poliéster, una carga de carbonato cálcico y un aditivo).

\subsection{Montaje de las partes que conforman la pila: el vaso y el fuste}

Las tres partes que conforman la pila bautismal, el vaso, el fuste y la basa, fueron manipuladas por separado a lo largo de todo el proceso de intervención. El montaje exigió una total coordinación del personal, para poder ensamblar "a plomo" las distintas piezas de la pila. El fuste fue colocado sobre la basa y unido mediante un mortero inorgánico de cal y carbonato cálcico. Asimismo, se colocó en la espiga del fuste un collarín de acero inoxidable ( $4 \mathrm{~mm}$ grosor) revestido por ambas partes con fieltro de caucho. Ello mejoraría el ajuste entre el fuste y el vaso, además de repartir uniformemente la carga de ésta sobre el fuste inicialmente fragmentado. La colocación del vaso sobre el fuste se procedió de manera gradual y lentamente. Una vez ajustado el fuste y el vaso, la unión superficial se selló mediante mortero de matriz sintética [figura 10]. Esta fase fue la más comprometida y delicada del conjunto de tareas realizadas. Durante siete días la estructura metálica portante se mantuvo instalada de manera preventiva y se supervisó regularmente el asentamiento de la taza y la adaptación del fuste. Finalmente, la estructura se eliminó al no detectarse anomalía alguna.
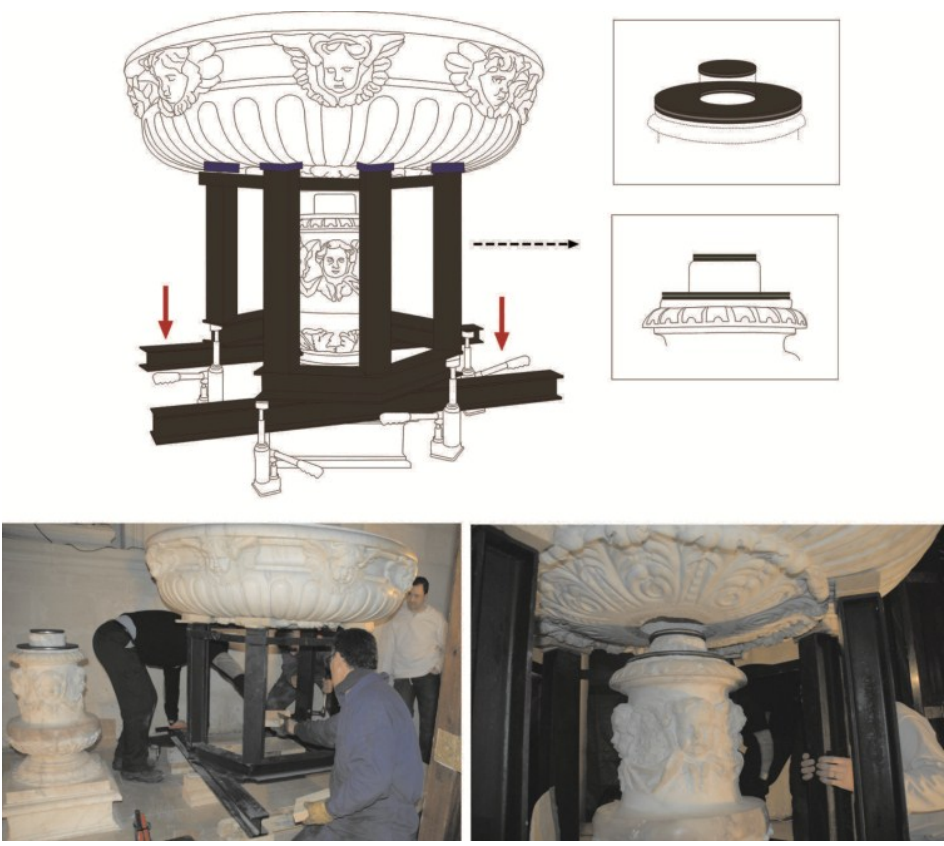

Figura 10. Fase de preparación para la colocación del vaso sobre el fuste. Obsérvese las piezas a modo de collarín de acero inoxidable revestido de caucho colocadas en la espiga del fuste. En la imagen puede observarse el preciso instante de orientación y encaje del vaso en la espiga del fuste. 


\subsection{Protección final del conjunto}

Concluidas las fases de limpieza, tratamiento volumétrico y montaje, se procedió a aplicar una fina capa de cera mineral microcristalina (Cosmolloid 80 de CTS/WS, 50\%), a muñequilla, como protección final. Con esta protección se pretende preservar a la pieza de posibles agentes y factores de alteración [figura 11]. Además, la elección de este sistema de protección confiere al soporte pétreo un juego de brillos acordes al estilo de la obra.
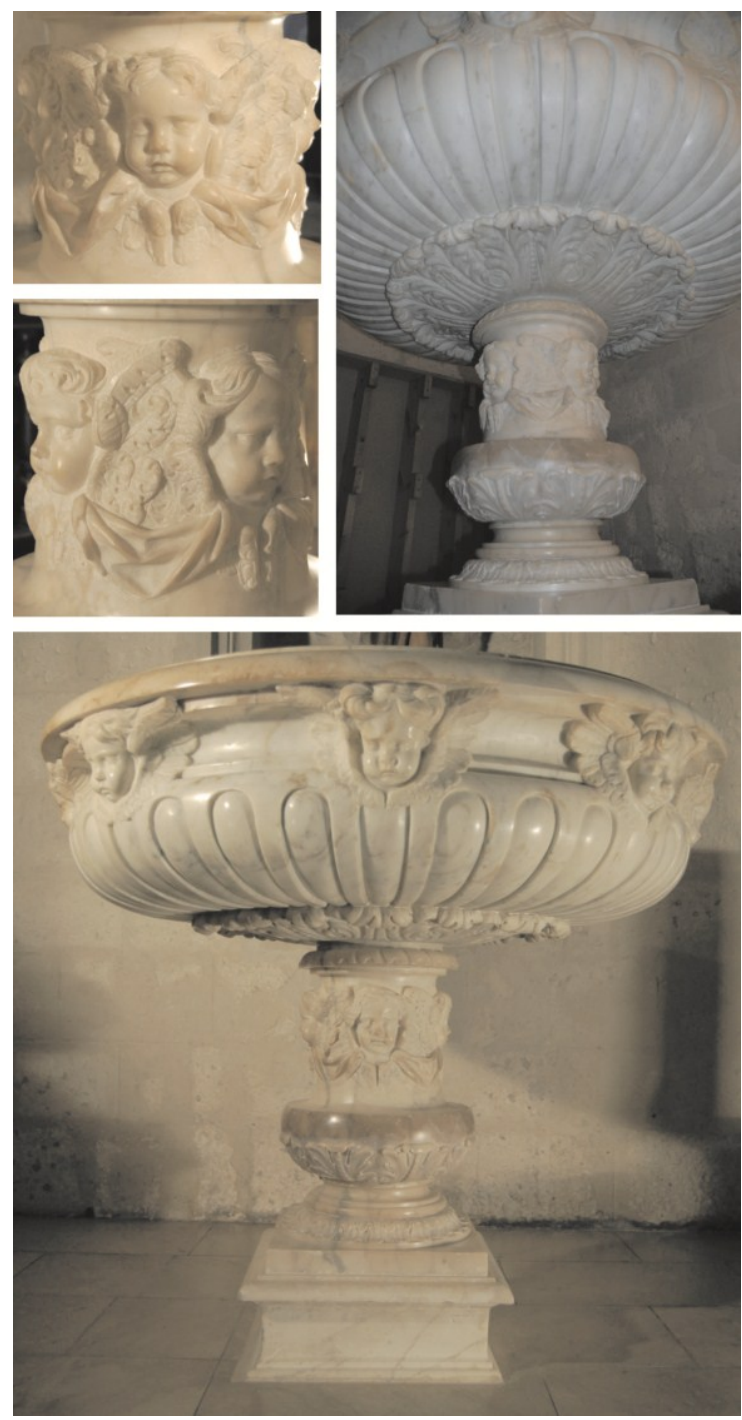

Figura 11. Detalle de los querubines alados localizados en el fuste donde inicialmente se percibía una grieta longitudinal. Detalle de los querubines localizados en el fuste tras la intervención. Vista inferior de la pila tras la intervención. Pila bautismal tras la fase de protección.

\subsection{Medidas preventivas y restablecimiento de la actividad litúrgica}

Las actuaciones de mantenimiento y conservación preventiva en materiales pétreos se centran en conseguir eficacia y duración de los resultados obtenidos en las etapas de conservación y restauración activa de las obras, así como frenar el creciente ritmo de deterioro del soporte pétreo, actuando sobre los agentes de deterioro que lo generan. Para ello, y como medida preventiva que permitiera restablecer la funcionalidad y garantizara la estabilidad del material original, se diseñó una estructura de sacrificio reversible obtenida a partir de una lámina de metacrilato de un centímetro de espesor y, fijada a ésta, un 
Xavier Mas-Barberà y María Duréndez-Hernández

La restauración en situaciones límite de pérdida estructural. La imponente pila bautismal renacentista de la Iglesia de Santa María de Ontinyent (Valencia)

módulo semiesférico de contención de sesenta centímetros de diámetro [figura 12]. Este sistema preventivo permite llevar a cabo la actividad litúrgica del bautismo así como admirar la obra sin apenas interferencias formales. Finalmente, se mejoró la iluminación de la capilla y se construyó una tarima de madera noble que permite el acceso a la obra, hecho que mejora la funcionalidad y la estética del conjunto [figura 13].
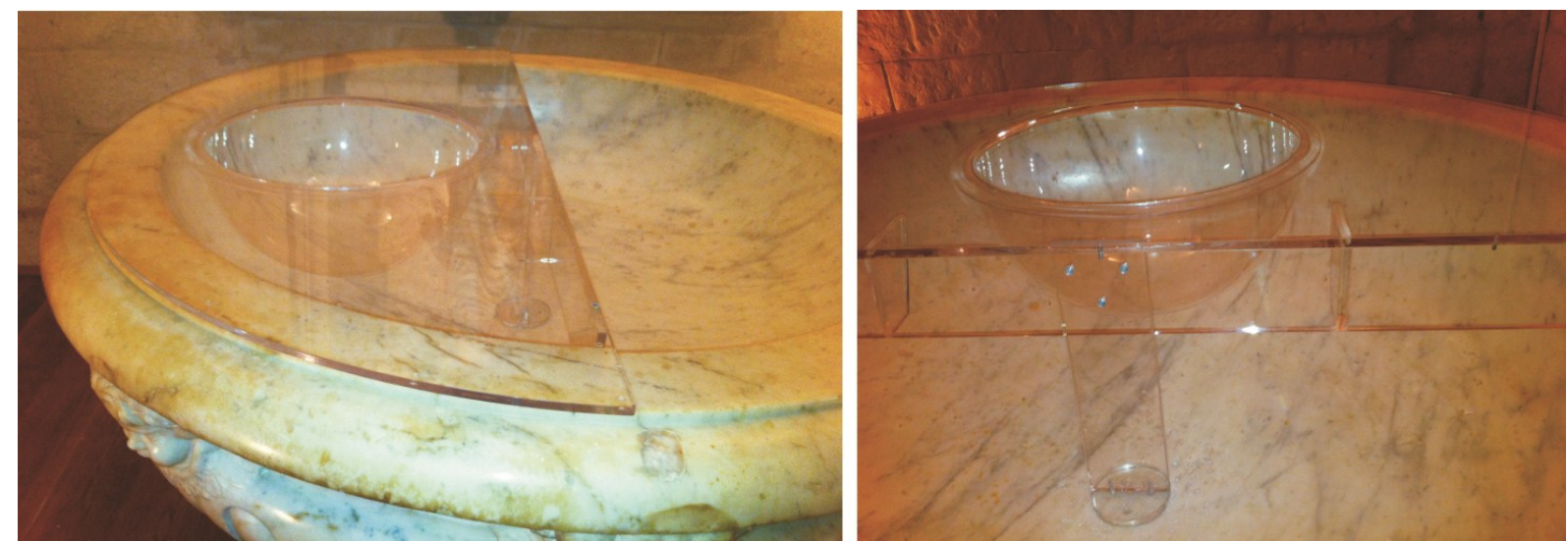

Figura 12. Estructura de sacrificio reversible realizada con metacrilato que permite restablecer la funcionalidad de la pila bautismal y garantizar su permanencia.

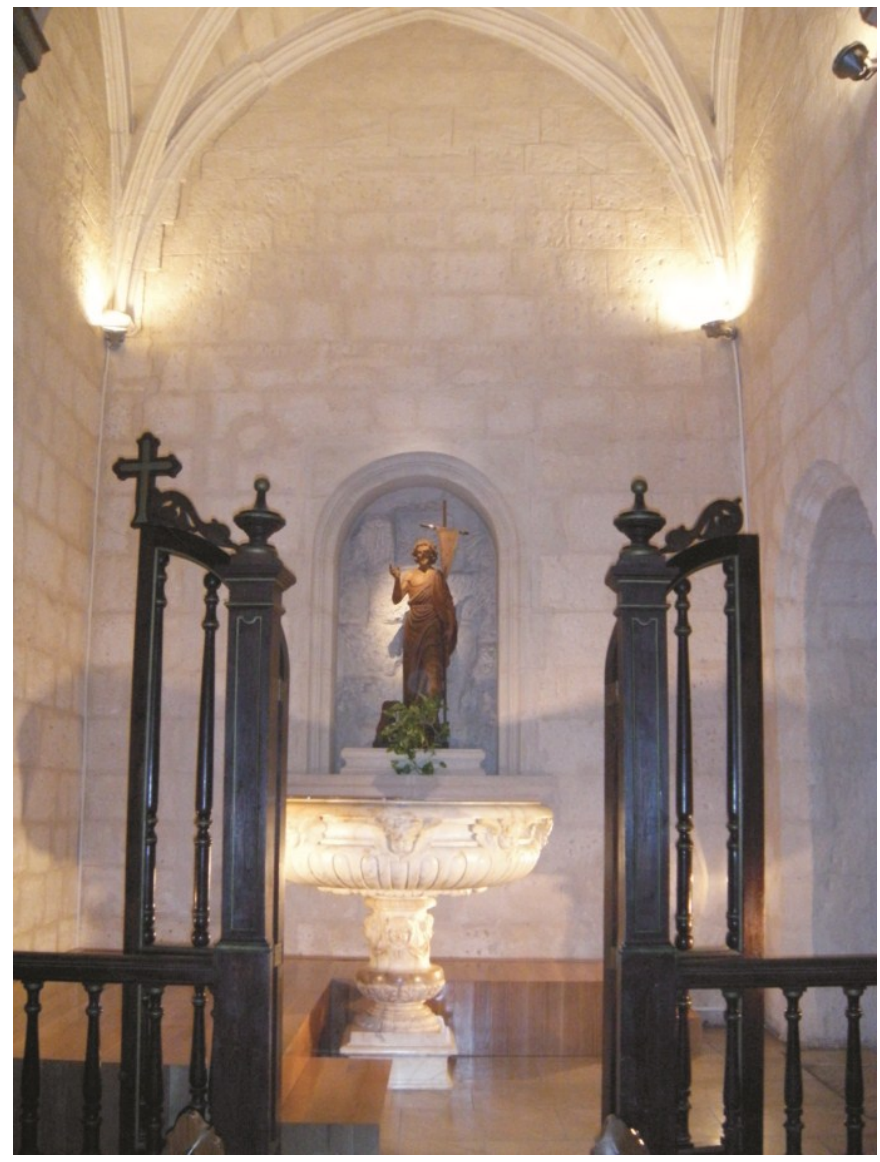

Figura 13. Vista general de la capilla con las nuevas medidas adaptadas al culto litúrgico (2009). 


\section{Conclusiones}

El tratamiento llevado a cabo sobre la pila bautismal de la iglesia de Santa María de Ontinyent, junto con la actuación en la capilla, ha permitido recuperar una obra única de valor excepcional.

Un hecho importante a destacar en dicha actuación ha sido la oportunidad de formar parte de un equipo multidisciplinar y compartir con ellos esta experiencia de trabajo. El equipo estuvo formado por ingenieros, arquitectos, restauradores, químicos, geólogos e historiadores, que ha hecho posible desarrollar una actuación rigurosa técnica y formalmente, devolviéndole al conjunto su integridad material.

\section{Agradecimientos}

Este trabajo ha sido financiado por la Iglesia de Santa María de Ontinyent y la participación del proyecto de investigación I+D+I de la Universitat Politècnica de València, PAID-06-08 Ref. 3247.

\section{Equipo de trabajo}

Coordinación general y responsable actuaciones:

Xavier Mas i Barberà $\quad$ Dr. en Bellas Artes. Profesor contratado Doctor. Especialidad en restauración

Colaboradores:

Ignasi Gironés Sarrió

Jorge Álvarez Afanador de materiales pétreos.

$\mathrm{M}^{\mathrm{a}}$ Ángeles Martínez

Ldo. en Bellas Artes. Técnico superior de apoyo a la investigación

Ldo. en Bellas Artes. Especialidad en restauración.

Maica Hernández

Lda. en Bellas Artes. Especialidad en restauración.

Estudiante de Bellas Artes. Especialidad en restauración.

Taller de intervención en elementos escultóricos y ornamentales:

Jose Vicente Grafiá Sales Dr. en Bellas Artes. Profesor contratado Doctor.

Análisis materiales pétreos:

Stephan Króner Dr. en Geología. Técnico del laboratorio de materiales pétreos.

Análisis físico-químico y medioambiental:

$\mathrm{M}^{\mathrm{a}}$ Teresa Doménech Carbó Dra. en Ciencias Químicas. Catedrática universidad.

Laura Osete Cortina Dra. en Ciencias Químicas. Técnico de laboratorio físico-químico.

Cálculo y diseño estructura portante:

Ángel Mas Barberà Ingeniero Técnico de Obras Públicas. Asesor y consultor técnico.

Colaboración técnica

Empresa Gruas Bellod, SL. Ontinyent.

\section{Notas}

[1] El conocido mármol de Carrara se presenta en una gran variedad con características cromáticas y estructurales diferentes. Por su variedad cromática se pueden agrupar en siete tipos: el blanco o estatuario, el Venato, el arabescado, el Calacata, el Bardiglio y el Cipollino Zerbino. En concreto, el carrara bardiglio es un mármol de color gris debido a la textura de la roca llena de impurezas. Se extrae de las canteras de la famosa población de Carrara, en Italia.

\section{Bibliografía}

ALCALDE MORENO, M. VILLEGAS SÁNCHEZ, R. (2003). Indicadores de alteración de los materiales pétreos. Granada: Ediciones Cuadernos técnicos no 8 . Instituto Andaluz de Patrimonio histórico. 
Xavier Mas-Barberà y María Duréndez-Hernández

La restauración en situaciones límite de pérdida estructural. La imponente pila bautismal renacentista de la Iglesia de Santa María de Ontinyent (Valencia)

ALCALDE MORENO, M.; VILLEGAS SÁNCHEZ, R; FRANCISCO VALE, J; MARTÍN PÉREZ, A. (1990). Diagnosis y tratamiento de la piedra. Madrid: Ediciones Instituto Eduardo Torroja /Centro Superior de Investigaciones Científicas.

ARMAND-THIERRY PEDRÓS, E. (2003). Vocabulari de talla en pedra. Valencia: Ediciones Monografíes de la Universitat Politécnica de Valencia.

AAVV, Alba, revista d'estudis comarcals de la Vall d'Albaida (núms. 1-15).

AAVV, Almaig, revista editada per la comissió de publicacions de La Nostra Terra.

BERnABEU, A., (1988). Arte e historia en la iglesia de Santa María de Ontinyent, Ontinyent: Caixa d'Estalvis d'Ontinyent.

BURNS, R. I. (1981). Jaume I i els valencians del segle XIII. Biblioteca d'estudis I investigacions. València: Tres i Quatre.

CARAYOL MARTÍNEZ, A. (2009). Estudio de resinas epoxi en uniones adhesivas lapideas. El caso de la obra "El Torso" del escultor valenciano Vicente Ortí. Valencia: Tesis final de Máster en Conservación y Restauración de Bienes Culturales, Universidad Politécnica de Valencia.

Catàleg general del Servei de Publicacions de l'Ajuntament d'Ontinyent (1985). Ontinyent: Servei de Publicacions

Catàleg de publicacions de la Caixa d'Estalvis d’Ontinyent.2011

GÓMEZ DE TERREROS GUARDIOLA, G.; ALCALDE MORENO, M. (2000). Metodología de estudio de la alteración y conservación de la piedra monumental. Sevilla: Ediciones Universidad de Sevilla.

LÓPEZ JIMENO, C. (1996). Manual de rocas ornamentales: prospección, explotación, elaboración y colocación. Madrid: Ediciones Entorno gráfico.

MARTÍNEZ SÁNCHEZ, R. (1984). La iglesia arciprestal de Santa María: sobre la recuperación de la fábrica gótica. Ontinyent: Programa-revista de las Fiestas de la Purísima.

MAS I BARBERÀ, X. (2010). Conservación y restauración de materiales pétreos. Diagnóstico y tratamiento. Valencia: Ediciones Universidad Politécnica de Valencia.

OSETE CORTINA, L., MAS-BARBERÀ, X., MARTÍNEZ BAZÁN, M.L., CARAYOL-MARTÍNEZ, A. (2009). Estudio del comportamiento mecánico y de los cambios cromáticos y morfológicos de resinas epoxi en uniones adhesivas lapídeas. Aplicación a una obra de arte mueble. En Actas del Congreso Tendencias en adhesión y adhesivos. Bioadhesión, bioadhesivos y adhesivos naturales. Edita José Miguel Martín. Laboratorio de adhesión y adhesivos. Dpto. de química inorgánica. Universidad de Alicante, pp.97.

PRICE, M. (2008). Rocas ornamentales: identificación, usos, geología, asociaciones históricas. Barcelona: Ediciones Blume.

VVAA (2003). Criterios de intervención en materiales pétreos. Conclusiones de las jornadas celebradas en Febrero de 2002 en el Instituto de Patrimonio Histórico Español. Madrid: Ediciones Revista del I.P.H.E. n².

VVAA (1998). Arte: Materiales y conservación. Madrid: Ediciones Fundación Argentaria, Col. Debates sobre arte.

VAILLANT CALLOL, M.; DOMÉNECH CARBÓ, T.; VALENTÍN RODRIGO, N. (2003). Una mirada hacia la conservación preventiva del patrimonio cultural. Valencia: Ediciones Universidad Politécnica de Valencia.

VILLEGAS SÁNCHEZ, R.; BAGLIONI, R.; SAMEÑO PUERTO, M. (2000). Criterios generales de intervención en materiales pétreos: Tipología de materiales para tratamiento. Sevilla: Ediciones Instituto Andaluz de Patrimonio Histórico. 


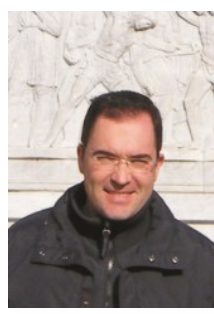

Xavier Mas i Barberà

Universitat Politècnica de València

jamasbar@upvnet.upv.es

Doctor en Bellas Artes por la Universitat Politècnica de València. Conservador-restaurador especialista en el ámbito de la conservación y restauración de materiales pétreos y, desde 2003, docente e investigador adscrito al Departamento de Conservación y Restauración de Bienes Culturales y al Instituto Universitario de Restauración del Patrimonio en la Universitat Politècnica de València.

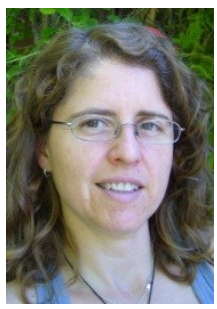

\section{María Duréndez Hernández}

Licenciada en Bellas Artes, especialidad en Conservación y Restauración de Bienes Culturales, por la Universitat Politècnica de València. Actualmente cursa el Master Ciencia y Restauración del Patrimonio Histórico-Artístico, en la misma universidad, en fase de investigación del Trabajo Final de Master.

Artículo recibido el 31/03/2011

Artículo aceptado el 17/08/2011 